\title{
"Treading in sand": A qualitative study of the impact of austerity on inequalities in mental health
}

Kate Mattheys, Faculty of Health Sciences and Sport, University of Stirling

Jonathan Warren, Institute of Health and Society, Faculty of Medical Sciences, Newcastle University

Clare Bambra, Institute of Health and Society, Faculty of Medical Sciences, Newcastle University

This is the peer reviewed version of the following article: Mattheys K, Warren J, Bambra C.

"Treading in sand": A qualitative study of the impact of austerity on inequalities in mental health. Social Policy and Administration 2018;52:1275-1289, which has been published in final form at https://doi.org/10.1111/spol.12348. This article may be used for non-commercial purposes in accordance With Wiley Terms and Conditions for self-archiving. 


\section{Abstract}

Successive UK governments since 2010 have adopted policies of austerity characterised by public spending and social security cuts. There has been little qualitative research exploring the effects of these policies on inequalities in mental health. This paper presents findings from a case study of Stockton-on-Tees, a local authority in the North East of England with exceptionally high spatial and socio-economic inequalities. Qualitative interviews were undertaken with people experiencing mental health problems in different areas of the local authority, alongside interviews with key stakeholders. The findings offer an insight into spatial inequalities in people's lives, and the impact of deprivation on mental health. They suggest that austerity measures are having a damaging impact on individuals and communities in the most deprived areas of this unequal place, whilst leaving those from less deprived areas relatively unscathed - with the exception of increased job insecurity. The cuts in social security are impacting on health through both material and psychosocial pathways including increased financial hardship and chronic stress. The intrusion of the state into people's everyday lives was such that the notion of the 'home as an asylum' was broken, giving many no respite from the draining day-to-day experiences of poverty. The findings are discussed in relation to the continuing programme of welfare changes and public spending cuts in the UK, including avenues for further research and key recommendations for policy makers.

Keywords: health inequalities; social determinants of health; social policy; neighbourhood effects

\section{Introduction}

The United Kingdom (UK) government's policies of austerity that were implemented following the global financial crisis of $2007 / 08$ led to significant concerns about the mental health costs of these measures (Barr et al, 2015). Key targets have included cuts in public services and 
investment in public infrastructure, with the social security bill being particularly hard hit (Lupton, 2015). Whilst there has been debate around the extent to which the government's approach to social security marked a change (or signalled continuity) from the previous New Labour approach (Patrick, 2015), austerity has seen a further entrenchment of the neoliberal model and has been characterised by heavy cuts to welfare services and benefits, an NHS funding freeze, and extensive cuts to government budgets (Bambra and Garthwaite, 2015). The government's objectives included leading the UK towards lower public spending, lower debt, and market led growth, and to shift responsibility in many areas from the state to the private sector, individuals, and communities (Taylor-Gooby, 2012). The programme of 'welfare reforms' has been substantial and has included a focus on the need to end 'welfare dependency', to return 'responsibility' to the benefits system, and to 'incentivise work' (Patrick, 2015). People who are not in paid work have been increasingly positioned as to blame for their situation, with a divisive rhetoric between 'shirkers' and 'strivers' applied to those on a low income (Garthwaite, 2011).

Disabled people, including those experiencing mental distress and mental health service users, are amongst those heavily affected by the social security cuts (Duffy, 2013). The 'reforms' have been numerous but have included reductions in housing and council tax benefit (such as the bedroom tax), increased conditionality and benefit sanctions, and more stringent medical tests for Employment and Support Allowance (ESA), a benefit that replaced Incapacity Benefit (IB). Post 2010 cuts to ESA entitlement and eligibility have included time-limiting nonmeans tested access to the benefit (people in the Work Related Activity Group who are too ill to work are now only able to receive the benefit for a certain period of time). The changeover from Disability Living Allowance (DLA) to the new Personal Independence Payments (PIP) has led to more stringent medical tests and a similar move towards time-limited awards (Beatty and Fothergill, 2013). The Work Capability Assessment (WCA) has come under particular criticism since its inception, with its viability and credibility heavily criticised by the people assessed under it (Warren et al, 2014). The ESA was initially introduced in 2008 by the Labour 
government with a primary focus on job activation. However it was implemented and reformed from 2010 onwards and forms part of a wider raft of benefit cuts. Mental health charities have voiced widespread concerns that the process is damaging people's mental health (Mind, 2012), and media reports have linked the WCA to numerous deaths (Warren et al, 2014).

The effects of austerity have not been distributed evenly, either spatially or socially (Bambra and Garthwaite, 2015). Across the UK the local authorities hardest hit by government spending cuts are those in the most socially disadvantaged areas (Pearce, 2013). An analysis of the spatial impact of the welfare cuts has identified that the most affected areas have included the older industrial areas of England, Scotland and Wales, with the North East of England firmly falling within this category (Beatty and Fothergill, 2016). Virtually all of the welfare cuts (with the exception of changes to child benefit for the wealthy) have been targeted at people already living in poverty (Duffy, 2013). This suggests that the welfare cuts - to both in and out-of-work benefits - have been regressive, bearing most heavily on the most deprived local authorities and on those on the lowest incomes (Hills, 2014).

Health inequalities are closely connected to social inequalities and so a widening of social inequality, as a result of austerity, may lead to a widening of social and spatial health inequalities. Both physical and mental health follow a social gradient: the higher an individual's social and economic position, the better their health (Marmot et al, 2010). Mental health has been consistently associated with factors related to material deprivation (Melzer et al, 2009). The consequences of living in poverty, including the impact of unemployment, underemployment, debt, poor living conditions, and living in areas with high levels of deprivation, can all increase risks to mental health (Rogers and Pilgrim, 2003). Furthermore, health inequalities research shows a link between psychosocial stress and adverse health outcomes including mental well-being (Bartley, 2008). 
National level research suggests that since 2010, inequalities in mental health may have worsened in the UK. Analysis by Barr et al (2015) found that between 2009 and 2013, inequalities in mental health between people with low levels of education compared to high widened by 1.29 percentage points for women and 1.36 percentage points for men. This increase was only partly explained by unemployment and wages (Barr et al, 2015a). Further, people living in more deprived areas have seen the largest increases in poor mental health (Barr et al, 2015b). A study of self-harm identified that 'economic hardships resulting from the recession and austerity measures accumulated or acted as a 'final straw' to trigger self-harm', and that changes in welfare benefits may have contributed to this rise (Barnes et al, 2016: 1). Internationally, Niedzwiedz et al. (2016) found that reductions in spending levels or increased conditionality may adversely affect the mental health of disadvantaged social groups. These increasing inequalities have been partly attributed to the 'welfare reform' programme, as a result of reducing incomes for those on the lowest incomes in society (material pathway), and the impact of increasing financial insecurity on stress (psychosocial pathway) and on mental well-being (Barr et al, 2015b). Those on low incomes - who are more likely to have worse mental health - are being made poorer, leading to worsening mental health.

An emerging body of qualitative research has explored the impact of austerity on people's lives, with findings suggesting increased material pressures, increasing insecurity, and a negative impact of damaging media and political portrayals of people who are in receipt of outof-work benefits (Pemberton et al, 2014). Dominant narratives position those out of work as 'feckless' and as making poor 'lifestyle choices'; these negative portrayals have been found to have a damaging impact on mental health (Garthwaite, 2016). Social security cuts have led to increasing levels of stress, worry and anxiety for people (Patrick, 2015). The difficulties created by managing on such a restrictive income, and with increased insecurity in the benefits system, have been reported as an endless and unremitting pressure (Pemberton et al, 2014). 
One of the key themes emerging from the qualitative literature is the negative impact the welfare cuts are having on mental health. Evidence from the voluntary sector suggests that the welfare cuts are also having a damaging impact on people who have pre-existing mental health problems (O'Hara, 2013). However, there is a lack of academic research exploring this, and considering the lived experiences of austerity between those with mental health problems living in more or less deprived areas. Although there are social gradients in health (Marmot et al, 2010), experiences of mental health problems exist across the social spectrum. The impact of austerity on people's lives is likely to differ between those from different socioeconomic backgrounds (Bambra, 2016). This research addresses the gap in the literature, examining inequalities in the lived experiences of austerity between people with mental health problems living in different neighbourhoods of one particular place in the North East of England.

\section{Methodology}

\section{Study Context}

The research has been located within a five year interdisciplinary case study that has attempted to explore key debates around health inequalities in Stockton-on-Tees in the North East of England, and evaluate the impact of austerity driven policies on these inequalities. This research developed out of the findings from a cross-sectional survey exploring inequalities in mental health and well-being between people from the most and least deprived areas of Stockton-on-Tees ([removed for anonymity], 2016). Qualitative interviews were subsequently undertaken with people from the survey who self-identified as having mental health problems. Additional interviews were undertaken with people with mental health problems who were accessing support from the local Citizens Advice Bureau (CAB). The findings were triangulated with interviews with key stakeholders in the local authority. 
Stockton-on-Tees is a particularly important case because it has such high spatial inequalities. In fact it has the highest health inequalities of any local authority in England both for men (at a 17.3 year difference in life expectancy at birth) and for women (11.4 year gap in life expectancy) (Public Health England, 2015). It was originally a market borough (and Stockton is still a market town), however from the $19^{\text {th }}$ Century, iron working, steel production, shipbuilding and railway industries, manufacturing and engineering all prospered in Stocktonon-Tees (Beynon et al, 1994). In the early $20^{\text {th }}$ Century the chemicals industry also saw major development, with the formation of Imperial Chemical Industries (ICI) in Billingham in 1926. From the 1970s onwards, however, recession, combined with processes of deindustrialisation, led to rising unemployment and a severe decline in the old industrial economy. Although some industry remained, there was a shift towards a service economy (Beynon et al, 1994), and a significant growth in public sector employment. This shift in labour market was not fully successful however, with levels of unemployment remaining a significant problem (Beynon et al, 1994).

Today Stockton-on-Tees has a population of 191,600 residents (Office for National Statistics, 2011). Stockton has high levels of social inequality, with some areas of the borough being particularly affluent and others with high levels of deprivation (Joint Strategic Needs Assessment, 2013). Following the global 2007/08 financial crisis, the recession that followed witnessed an above average rise in unemployment (Nomis, 2012), alongside cuts in local authority spending and reductions in public sector employment (Hudson, 2013). Unemployment continues to be a problem, with Office for National Statistics job density figures for 2015 demonstrating a lack of jobs per resident (Nomis, 2015). $6.9 \%$ of the population are in receipt of ESA or IB (Nomis, 2016) and 1.4\% receive either DLA or PIP (Department for Work and Pensions, 2017). In the 2011 Census, the most affluent areas of Stockton had an unemployment rate of $5.1 \%$ (compared to a national rate of $6 \%$ ), only $4.3 \%$ of people reported that they were in bad or very bad health (compared to $6 \%$ nationally), and $19.2 \%$ of people reported a long-term health problem or disability (compared to $18 \%$ nationally). In contrast, 
$27.1 \%$ of people in the most deprived areas of Stockton are unemployed, $12 \%$ of people reported that they were in bad or very bad health, and $26.5 \%$ of people have a long-term health problem or disability (Office for National Statistics, 2011).

\section{Data Collection and Analysis}

Semi-structured interviews remain an extensively used research method (Roulston, 2010). They are steeped within the narrative tradition (Gudmundsdottir, 1996). People tell stories of their experiences, using a narrative structure. It is the role of the researcher, through a process of interaction, to co-operate with the interviewee to jointly piece together these stories and develop a shared meaning (Mishler 1986 in Gudmundsdottir, 1996). This approach can tell stories of individual experiences, and reveal an understanding of the identities of individuals, how they see themselves and how they construct their understanding of the world around them (Cresswell, 2013: 48). People experiencing mental distress have often had their voices marginalised (Menzies et al, 2013). The 'hierarchy of credibility' (Becker, 1967: 241) has meant that preference has often been given to the narratives of people providing the services as opposed to those receiving them.

Semi-structured interviews were completed with 28 participants (17 participants with reported mental health problems, and 11 key stakeholders). The participants in the wider crosssectional survey who self-reported as having mental health problems (they were asked whether they had any longstanding physical or mental health problems and asked to specify) formed the sampling frame of participants to take part in the semi-structured interviews. This included 56 participants (20 in the least deprived areas and 36 in the most deprived). A sample of participants, mixed between respondents from the most and least deprived areas of Stockton-on-Tees (identified from the Indices of Multiple Deprivation, 2010), was drawn to undertake further interviews, using a theoretical sampling approach. Links were also 
developed with the $\mathrm{CAB}$ in Stockton and additional participants were recruited from there, to capture the specific experiences of people who were being supported with welfare advice, and to compare the findings with those from the most and least deprived areas.

There were ten women and seven men in the sample. Five participants were recruited from the most and seven from the least deprived areas of Stockton-on-Tees, and five participants from the CAB. Participants were aged between 27 and 62 years, although the majority were in their 40s and 50s. All participants reported having longstanding (in most cases over many years) problems with their mental health. In the most deprived/CAB groups, two participants were in paid employment, two participants were in receipt of Job Seekers Allowance (JSA), and six participants received either ESA or IB. Four participants received DLA/PIP. In the least deprived group, four participants were in paid employment, one participant was in receipt of JSA, and two participants were recently retired.

The interviews covered the following areas: personal experiences of the benefits system; employment/training/education; mental health support; physical health; social support; leisure; relationship with place; coping strategies. A voice recorder was used and the transcripts were fully anonymised and coded following each interview. Written informed consent was gathered from all participants. Participants were provided with a detailed information sheet and given the opportunity to withdraw from the research at any point. The main analytic framework was thematic analysis. The majority of participants were interviewed in their own homes, although two interviews took place in a university office and one further interview was by telephone. The interviews took place in a six month period between March and September 2015. The length of interviews generally took one hour, although ranged between 45 minutes and two hours.

The 11 stakeholders were recruited using a purposive sampling strategy and came from a range of backgrounds, including advocacy, welfare advice, the local authority, supported 
accommodation for homeless people and people with drug and alcohol problems, mental health drop in centre, psychology, community action organisation, and a mental health organisation operating in the local authority. The interviews with stakeholders took place in a 3 month period between May and July 2016, a year later than the interviews with participants with mental health problems. The same procedures were used for gathering informed consent, anonymising the data, and data coding and analysis. Ethical approval for the research was granted by the Ethics Committee at [removed for anonymity] University.

\section{Findings}

The results of the interviews demonstrate the relationship between poverty, financial security (or insecurity), and mental health. Additionally, austerity and related welfare cuts impacted on the mental health of people with pre-existing mental health problems, particularly in the most deprived areas and via material (worsening financial situations) and psychosocial (chronic stress) pathways.

The Daily Struggle? Financial (in)security and the impact on mental health

Whilst participants from the least deprived areas generally reported financial security, money worries were an issue for many of those who were recruited from the most deprived areas and CAB. Participants talked about the significant stresses of struggling financially, of worrying about how they would pay bills, of how they would be able to cope. They reported how financial insecurity had worsened significantly since 2010 and how managing on a day to day level had become increasingly difficult. An analysis of poverty in the United Kingdom between 2010 and 2015 identified that for people at the lower end of the income scale, there are increasing numbers of people whose material circumstances are significantly worse than they were 5 years ago (Maclnnes et al, 2015). 17.4\% of the population is now unable to afford 
three or more items from a list of nine everyday items such as a washing machine or healthy meal; two thirds of low income working age couples without children cannot afford at least one item (Macinnes et al, 2015). Paul lived with his girlfriend and they were both out of work. His physical and mental health problems meant that he was not currently able to work. Paul missed work and the social and economic benefits of this. He described how the couple's income was not enough to meet their basic needs, and the stress that this caused him:

It's not enough to live on. Cause we get, what, a hundred and forty a fortnight, for the two of us to live on, and that's nothing... It makes you anxious thinking how am I going to live, how am I going to afford this, and that's another thing that doesn't help with depression and that either. (Paul, 27)

Many participants discussed food as one outgoing in which they now made savings. Participants talked about strategies they had come to rely on such as going without, or buying cheaper food, to ensure that they were still able to pay their bills. Jimmy talked about how the family had to rely on food that was less nutritious because it was within budget:

I wouldn't say there's nowt in my fridge but there's nothing like, of any nutrition. So if anything suffers, I pay my bills, but we don't eat brilliant. You know, beans, hot dogs, toast. Even just a simple piece of meat, beef, well that's kind of money spent better elsewhere. So you find yourself categorising things. So as long as you've got a bit of food in the cupboard. But that works on a fortnightly basis, you know what I mean. (Jimmy, 47)

In contrast to the challenging financial situations of participants in the most deprived areas, those in the least deprived areas were on the whole comfortable financially: they did not present as worrying about money and saw the 'cost of living' as either something they had not considered or something that was now improving. Jen commented: 
I'm one of the lucky ones. I can just go out, and this sounds awfully like you're bragging and I'm not, basically we can buy what we want, you know... We have no money worries or anything now, and I think that's helping. Just being more relaxed. (Jen, 62)

These participants did not see themselves as being particularly affluent but felt that they had enough to get by. Within the determinants of health literature, income is important in the relationship between socio-economic status and health because it enables access to goods and services, and allows people the ability to avoid exposure to physical and psychosocial risk factors (Bambra, 2016). Having more money meant that participants were able to access a range of opportunities that would benefit their mental health and give them a break from their day-to-day lives. Holidays were talked about as important. James, who discussed how his mental health always became worse over the winter, relayed how the wider family were considering buying property abroad:

We are chewing over getting somewhere in Spain. Winter time absolutely crushes me. I try not to let it affect me, but when we lose that hour and we go hurling into the winter time, I'm crushed. December, January, February, just trying to get through those three months. So between the three of us, if we do end up clubbing the money together, sixty grand between the family isn't that much. (James, 47)

Being financially stable gave participants options to find a 'way out' of situations that were detrimental to their mental health, such as taking early retirement or moving to part-time working. The participants who were over the age of 50 were more likely to have these options available. Brenda worked for Job Centre Plus (formerly the Department of Health and Social Security). As a result of the impact of increasing stress at work on her mental health, she had 
opted to move down to part-time employment. Although this would impact negatively on her final pension, she had made the decision to support her mental health:

I'm already on early retirement because I already do three days a week now, because my work life balance had gone. I'd done nearly forty years there, and I just thought, 'That's enough'. So I went partially retired about eighteen months ago. Best thing I ever did. (Brenda, 56)

This ability to use money to find a way out of a difficult situation was often not available to participants in the most deprived areas or those from the CAB. Pauline, a trustee in a community organisation, spoke about her experiences of going bankrupt, and the lack of choice she was faced with in terms of her housing and her husband's mental health:

When my husband was ill, we had to move, because I went bankrupt. We moved onto the council estate. I got the doctor in, and the doctor said 'he doesn't like living here'. I said 'I know, I don't like living here either, but there's nothing I can do about it'. People just say that poverty is a thing because you have no money. But it isn't. Poverty is a lack of choice. (Pauline, Community Organisation)

Keeping people in distress: the disproportionate impact of austerity

Features of the austerity programme, in particular the welfare cuts, were found to disproportionately affect those on the lowest incomes, and the most deprived communities. Narratives around austerity were - conversely - largely absent from the accounts of people living in less deprived areas. This was with the exception of employment, where people spoke about increasing job insecurity and increasing pressures. Dennis had spent his career in the civil service and discussed how austerity had impacted on his work at HM Revenues and Customs (HMRC): 
In 2010 you had the austerity. We had the austerity as well. So the money was cut, the expectations of bringing more money in was increased, and the training was pulled back... and that's the environment you're working in. So I felt like I was treading in sand. And it just meant you were going into work every day thinking 'God this is hard work'. It was all throughout the office... It was horrible, absolutely horrible. (Dennis, 57)

Whilst austerity had permeated into the work environment for those from the least deprived areas, it was pervasive in the accounts of participants from the most deprived areas. These participants had already been dealing with issues relating to long-term poverty and deprivation. Austerity had served to exacerbate those issues, creating significant difficulties that had an additional mental health burden. Key stakeholders also highlighted the financial impact of austerity measures on the communities in which they worked. Jill was the manager of a community organisation. Supporting people to find a way out of financial hardship was one of their key roles, however Jill reflected on how this had become increasingly difficult:

\footnotetext{
You can't build financial resilience, because people can't even get through one week. We used to deliver a money mentor programme, you'd increase income coming into the house, decrease expenditure, do a savings diary, look around for cheaper fuel. We can't do that now. Money mentoring has gone out of the window, we're dealing with crisis day in day out. (Jill, Community Organisation)
}

One of the key ways in which austerity was disproportionately impacting on people from more deprived backgrounds was via the social security system. For those in receipt of out of work or ill health/disability related benefits, they faced significant stress around not having enough money. This was linked to the concept of uncertainty, of not knowing when/if benefits were going to be paid and of the worry about how to make ends meet if they weren't. Whilst 
participants in the more deprived areas who were in paid employment talked about struggling financially, and increases to the cost of living, those who were in receipt of either JSA or ESA, or had been affected by changes such as the bedroom tax, were in the most precarious financial situations. Their financial situations had worsened since the onset of austerity. Laura had been affected by the bedroom tax and a new requirement to pay council tax. Laura's experiences place her in the same position as $9 \%$ of families across the UK who are unable to adequately heat their home (PSE UK, 2013):

I never used to pay bedroom tax, but now I pay £15 a week, plus we pay £22 poll tax... In the winter, it's like a battle, because these houses are really cold. So we can only afford to heat one room, which is this one [living room]. We can't afford to heat our bedroom, radiators cost, they are expensive to run. And you just don't have the money to do it. So mainly we live in the one room. (Laura, 53)

Although participants used strategies to try to cope with a lack of money, involvement with the benefits system led to chronic stress, which often aggravated the difficulties that people were already having with their mental health. Jimmy had a chronic back injury, and after having what he described as a breakdown ten years ago, had experienced ongoing problems with his mental health. He discussed his experiences of the medical assessment process before 2010:

It was kind of alright, I expected that I would be brought in for medicals and stuff. Which was fine, I was filling in the forms and l'd get there and l'd be examined and I'd get a letter saying 'that's fine, you're ok for two years' or something. So that was like a massive weight off my shoulders, and I was able to sort of focus. (Jimmy, 47) 
However, for Jimmy, since 2010 the continual loop of assessments and appeals that he had experienced (in particular in relation to the WCA) meant that he experienced the benefits system as relentless. He talked about being constantly worried about his benefits, whether he would lose them, and how he would be able to cope financially. This caused him chronic anxiety:

There's the stress of always worrying are they going to pay me this week? Am I going to be able to pay my bills? Of course in the meantime your rent goes into arrears, your council tax goes into arrears, it has a chain effect. It's relentless... you go to bed thinking about it and you wake up thinking about it... They had me in between Christmas and New Year one time. You can't imagine what that does for a person (Jimmy, 47)

The WCA has come under heavy criticism since its inception, with arguments that the process is not fit for purpose: nearly $40 \%$ of appeals lead to decisions being overturned (Barr et al, 2015a). Research has found an association between reassessments via the WCA and an increase in suicides, self-reported mental health problems and prescriptions in anti-depressant use (Barr et al, 2015a). As with Jimmy, other participants talked overwhelmingly about ESA as an on-going, revolving door process of failing medicals, appealing, passing appeals and then being reassessed within a very short space of time. Even when participants had passed an appeal it was only a matter of time before a letter arrived requesting a reassessment. Some participants kept going with the appeals (particularly those who were being supported by the $\mathrm{CAB}$ ), whereas others had given up and gone onto JSA. Lily had longstanding problems with her mental health, alongside physical ill-health and substance misuse issues. She talked about the stress involved in the benefits system (in Lily's case the medical assessments were undertaken by ATOS, although the contract for undertaking assessments has since been given to Maximus). Lily saw this stress from these processes as ultimately contributing to her drinking alcohol again: 
They keep taking me off Employment and Support Allowance and putting me on Jobseekers, saying that I'm capable of work. I've had three medicals with ATOS and got 0 points. Went to the CAB and they sorted it out and I got 15 points. It's just changed again... I don't know whether l'm coming or going. When l'm going to get paid. If I'm going to get paid... It's a nightmare... That's why I turned to the drink again. Because I was abstinent for fifteen years and it just... what I thought was relief. (Lily, 60)

The same relentless process of assessments was also described by stakeholders in relation to the transfer from DLA to PIP. Bill, a welfare rights stakeholder, spoke of how whilst most awards for the DLA were indefinite, the PIP awards are subject to regular review:

The biggest problem is renewals. Being renewed early, being refused, and having to go back through the system again. We were talking about how many cases we've got where we've gone to tribunal with somebody and they've got their renewal form a few weeks later, to start the whole process all over again. (Bill, Welfare Rights)

Many participants (from all groups) spoke about how, during periods where their mental and physical health was particularly bad, they would physically retreat into the safety of the home. In contrast to guidance suggesting that people should get out more and engage more socially to improve their mental health (e.g. NHS 2014), for a lot of the participants the opposite was true during a period of crisis: they felt they needed to be away from other people until they started feeling a bit better. Staying at home was a strategy that people used to ride out the worst of a difficult time: participants talked about shutting down, going to sleep, closing the curtains and 'seeing through' a period of distress. Avoiding the outside world was a coping strategy: 
I just used to put meself in bed, and sleep. I could sleep for days. I knew, if I'm asleep, I don't have to deal with reality, with what's going on. So I would just sleep and sleep. I would wake up and go to the toilet and get a drink of water and just go back to bed. I would lose literally a stone doing that. (James, 47)

For the participants in the study who were in receipt of out-of-work benefits, however, the intrusion into their home of the benefit system, in the form of regular letters notifying them about changes such as reassessments and appeals decisions, meant the concept of the 'home as an asylum' was broken. There seemed to be a relentless process of decisions being made, benefits stopped and changed, and the person having no real say about it. Alison spoke of this process and her sense of powerlessness, reflecting on the 'fear of the brown envelope', a theme highlighted in other research (Garthwaite, 2014):

Some days I just sit and I'm crying over absolutely nothing. And the postie comes and I see a brown envelope and I don't want to open it, because it's either the housing or the benefit, and it's just like, since all the changing over of the different benefits over the last couple of years, that's been the worst time for me, these last two and a half years to three years, benefit wise. (Alison, 50)

There were many instances of participants feeling 'unheard' and 'unlistened' to. For many the system came across as an arbitrary and unfair process without any grounding in the reality of their lives. Andy described a situation in which he was threatened with being sanctioned:

I've signed on today, I filled the form in as best as I can and I go on a job search on the internet. What else can I do? And she said 'It's not enough. We've got to sanction you'. And I don't know if she is or not. ... This triage, where I go, they're supposed to help me get a CV, but he said they haven't got the time. So that he'll 
just do us a little one. That's what he said. But it's no good. The dole are telling me it's no good. (Andy, 46)

This also meant that the benefits system could then become punitive, as described by a General Practitioner (GP) in relation to benefit sanctions:

People that are sanctioned are almost always people with mental health problems, and it almost always has a detrimental effect on their mental health. They're almost being punished for their chaotic lives. It's often being late for something, or not turning up for something [that leads to the sanction], but usually when you drill down to why somebody hasn't gone, it's this underlying anxiety, this fear, they're not necessarily just trying to gain the system by not going. (Peter, GP)

Stakeholders spoke about how the assessment process could be particularly challenging for people experiencing mental health problems. Bill, a welfare rights adviser, discussed how it is clients with mental health problems who face some of the most significant barriers. This was as a result of people's needs not being understood in the assessment process, and of communication difficulties that people had in expressing their needs. Bill outlined his fears about this drive towards reassessments for both PIP and ESA:

For people who have long term needs, I have real concerns that if they're being asked to have their benefit reconsidered on such a frequent basis, what likelihood is that person going to have the wherewithal the next time around, or the support mechanisms around them, to try and seek advice? You just need one time for that to fall apart, or you can't attend the medical, to lose your benefit. (Bill, Welfare Rights) 
Bill was highlighting concerns that there may be points at which people fall into crisis and become unable to cope with the on-going demands of the benefit system. Because of legislative changes that came into force on $30^{\text {th }}$ March 2015, people are also now unable to reclaim ESA if they have failed it once, unless they are able to show that their condition has significantly deteriorated (CPAG, 2015).

\section{Discussion}

The findings support a body of literature showing how poverty negatively impacts on mental health (Dreger et al, 2014; Curtis, 2010; Bartley, 2008; WHO and Calouste Foundation, 2014). Poverty is stressful. Poverty also prevented people from having the choice to participate in social and cultural life. Townsend's (1979) consensual view of poverty suggests that poverty is relative: minimum standards of living are identified by consensus amongst the general population around the goods and activities that are considered necessary in that society. People who are unable to achieve these standards are defined as in poverty. This relative poverty was revealed through the interviews, with both participants (from the most deprived areas and $\mathrm{CAB}$ ) and stakeholders discussing the daily struggles people faced in being able to get by. In this context the ability to participate in social activities was often beyond what people could afford. These lived experiences contrasted with the narratives of those living in less deprived areas, in which holidays and participating in varied social and community activities were commonplace, and were strategies they used to support their wellbeing.

Whilst all of the participants had experienced problems with their mental health, and those from the least deprived areas faced challenges in dealing with these issues, factors relating to poverty had a chronic additional impact on those from more deprived backgrounds. Income was a source of power, enabling those who were financially comfortable to find a route out of situations that were damaging their mental health. Conversely, for those participants who were living in poverty, feelings of powerlessness were regular themes. Lack of money 
significantly constrained the choices that were available. Feelings of not being listened to and being unheard came up regularly and this was reflected in people feeling powerless over decisions that were being made, and was particularly present for those who were in receipt of social security.

The findings add to the research base around how the global economic crisis in 2007/08, and resulting period of austerity, has impacted on local inequalities in mental health. National level research has shown growing inequalities in mental health in the UK (Barr et al, 2015). Widening mental health inequalities have been attributed to welfare cuts (principally as a result of reducing income amongst those on the lowest incomes), and to stress relating to the WCA (Barr et al, 2015b). In reality the WCA forms part of a long-term government strategy towards job activation and reducing the population of IB/ESA claimants. However the rollout of ESA to existing IB recipients took place from 2010 onwards, and by 2014 the Coalition government had proceeded with the reassessment of 1.5 million IB claimants, and implemented significant cuts in ESA entitlement and eligibility. This was despite continuing controversy and a 5 year review process (Daguerre and Etherington, 2014). This rollout also coincided with the announcement in $\mathbf{2 0 1 0}$ of austerity measures that included a host of other welfare cuts.

The link between austerity and mental health in this study was complex and included the impact of multiple issues including deteriorating financial situations, increased insecurity, feelings of powerlessness, and significant anxiety around what was to come in terms of loss of further income. Although all of the participants in this study reported mental health problems, the findings reveal the detrimental impacts of the welfare cuts on the mental health of those that have been affected by them. The scale and intensity of these cuts has had a profound impact on those affected by them. Receipt of in or out-of-work benefits was a key feature distinguishing the experiences of austerity between those living in more or less deprived areas: as 'welfare reform' has primarily targeted this group, it is expected that they would experience more negative effects of austerity. However alongside this there needs to 
be a consideration of the context in which people are living: there are additional impacts of living in deprived areas, and in the circumstances in which people are experiencing benefit cuts, that impact on mental health. This includes for instance the impact of lack of services, lack of decent jobs, crime, and environmental issues (Bambra, 2016). Indeed, there is evidence from the wider health and place literature which suggests that living in deprived areas can amplify the negative effects of poverty: the amplification of deprivation thesis (Macintyre et al, 2002).

Narratives around welfare cuts were (as might be expected) largely absent from the accounts of people living in less deprived parts of Stockton. However there was a notable exception in terms of the effects of rising job insecurity. This suggests that the effects of the $2007 / 8$ recession and the subsequent culture of austerity had also begun to affect even those with mental health problems living in relatively more affluent circumstances. This is of course part of a longer term trend in the rise of precarious work so that the precariat now is beginning to include even members of what might be seen as the comfortable middle-class (Standing, 2014).

The evidence base to date suggests that the welfare cuts have been particularly damaging to mental health (Patrick, 2015; Garthwaite, 2014; Warren et al, 2014). Two key features of the 'welfare reform' programme had a detrimental impact on mental health. Firstly, benefit cuts led to increasing deprivation. Evidence suggests that the welfare cuts have targeted the poorest in society (Maclnnes et al, 2015; Beatty and Fothergill, 2016; Duffy, 2013). Participants spoke of worsening finances and significant stress around managing on a reduced income. Secondly, there were direct mental health impacts of the benefits system: the impact of revolving door cycles of stressful assessments and reassessments; increasing conditionality; and oppressive processes that left people feeling in situations of powerlessness. The interviews revealed the chronic welfare system induced stress faced by those in receipt of certain benefits. This chronic stress links in with how the programme of 
welfare cuts have exacerbated inequalities in mental health, as they have only affected those on the lowest incomes.

Further, the findings add an important contribution to the specific challenges faced by people with mental health problems, building on the evidence base around the general mental health impact of the welfare cuts (e.g. Patrick, 2015). The findings suggest that the relentlessness of assessment processes is keeping people in distress. Stakeholders discussed how the benefits system could be punitive towards people experiencing mental health problems. This builds on previous research showing discriminatory experiences (Hamilton et al, 2016). Other qualitative research exploring the impact of welfare cuts has identified the 'fear of the brown envelope' (Garthwaite, 2014), a process in which people are left in constant levels of anxiety around letters regarding assessments, reassessments, and changes to benefits entitlement. However in addition to this, a new finding from this project was that many participants spoke about the need to retreat from social life when their mental health was particularly bad. For those in receipt of out of work or ill health related benefits, austerity permeated into the home, breaking that concept of the home as a safe space in which to retreat from the outside world. For those who did ignore this outside world, they risked punitive responses.

In 2016 the UK government announced moves towards ending reassessments for ESA for people with chronic illnesses (BBC, 2016). It is currently unclear how (and whether) this will affect people experiencing mental distress (DPAC, 2016). The findings from this study suggest that these processes are having a chronic impact, causing significant additional strain to the mental health of the people and communities that they are affecting. Whilst all of the participants in this study reported problems with their mental health, for those from more deprived backgrounds, the austerity programme had an on-going, adverse impact on their mental health. This had clear and detrimental effects on their daily lives. Stakeholders identified significant concerns that - alongside ESA - the regular reassessment process for PIP was also causing similar emotional harm, and it is of concern that people are now being 
faced with the stress associated with multiple reassessments. On-going changes to the benefits system, including wider reforms to Housing Benefit (capping the levels that can be claimed by social housing tenants to Local Housing Allowance rates) are likely to have a significant additional financial burden on this group, as this is likely to lead to shortfalls between rent due and entitlements to Housing Benefit (Wilson and Barton, 2016). The effects of these changes - which also include the transfer to PIP, rollout to Universal Credit, and the lowering of the benefits cap - on mental health - particularly amongst those with pre-existing mental health problems, will require further analysis.

\section{Conclusion}

This study bears witness to how the austerity programme has made a mark on the social landscape in one place, aggravating structural inequalities and having damaging consequences on communities that were already struggling with deprivation and ill-health. It gives voice to the lived experiences of austerity for those who are dealing with mental health problems in different neighbourhoods and from different backgrounds, demonstrating inequalities in their lives, and the particular challenges faced by those in more deprived communities. This adds an important contribution, showing how factors relating to deprivation (or lack of it) impact on people, alongside how the austerity-driven 'welfare reform' programme is undermining mental health, keeping people in distress, and having a chronic impact on people's lives. Since 2010 the implementation of ESA has seen greater conditionality, more stringent medical tests, and sits alongside a host of other cuts that have targeted the same people. These cuts have been deeply regressive and have taken place in a climate in which political and media portrayals of people on low incomes have become increasingly negative. These combine to impact on mental health through both worsening financial situations, and increasing emotional harm. 
Since the Brexit vote, there has been a slight change in tone with the focus on balancing the national budget abandoned. However, there has been little sign of the reversal of measures that have been instigated since 2010, and the programme of cuts continues. This includes the rollout of cuts in ESA for people judged able to take part in 'work related activity', and a limit of child tax credits to the first two children. The denial of housing benefit to young people aged eighteen to twenty one will also soon come into effect (Elgot and Mason, 2017). Remarks from the Institute for Fiscal Studies suggest that if, by 2019/20, the planned cuts in government spending continue, that 'the role and shape of the state will have changed beyond recognition' (Johnson, 2014: 5). The cuts to date have adversely impacted on social inequality, and on inequalities between the lives of people with mental health problems. Whilst those on the lowest incomes have borne the brunt of the austerity programme, residents at the other end of the income spectrum have experienced only minimal changes. It is this disproportionate impact that is aggravating inequalities in people's lives. A continuation of these policies is likely to have significant on-going impacts on both social and spatial inequality, and further damaging consequences to mental health. 


\section{References}

Bambra, C. (2016) Health Divides: where you live can kill you. Bristol: policy press

Bambra, C. and Garthwaite, K.A (2015) Austerity, Welfare Reform and the English Health Divide. Area 47:341-343

Barnes, M.C., Gunnell, D., Davies, R., Hawton, K., Kapur, N., Potokar, J., and Donovan, J.L. (2016) Understanding vulnerability to self-harm in times of economic hardship and austerity: a qualitative study. BMJ Open 6:e010131

Barr, B, Kinderman, P, and Whitehead, P (2015) Trends in mental health inequalities in England during a period of recession, austerity and welfare reform 2004-2013. Social Science and Medicine 147: 324-331

Barr, B, Taylor-Robinson, D, Stuckler, D, Loodstra, R, Reeves, A, Whitehead, M (2015b) 'First, do no harm': are disability assessments associated with adverse trends in mental health? A longitudinal ecological study. Journal of Epidemology and Community Health, 0: 17

Bartley, M. (2008) Health Inequality: An introduction to theories, concepts and methods. Cambridge: Polity Press

BBC (2016) ESA benefit payments: Re-tests axed for chronically ill claimants. $B B C, 1^{\text {st }}$ October, http://www.bbc.co.uk/news/uk-politics-37526324 (accessed 1.10.2016)

Beatty, C and Fothergill, S. (2013) Hitting the poorest places hardest. The local and regional impact of welfare reform. Centre for Regional Economic and Social Research: Sheffield Hallam University. http://www.shu.ac.uk/research/cresr/sites/shu.ac.uk/files/hitting-poorestplaces-hardest $0 . p d f$ (accessed 7.5.2014)

Beatty, C and Fothergill, S (2016) The uneven impact of welfare reform. The financial losses to places and people. Centre for Regional Economic and Social Research: Sheffield Hallam University http://www.shu.ac.uk/research/cresr/sites/shu.ac.uk/files/welfare-reform2016 1.pdf (accessed 21.3.16) 
Becker, H.S. (1967) Whose side are we on? Social Problems 14(3): 239-247

Beynon, H., Hudson, R., and Sadler, D. (1994) A Place Called Teesside: A Locality in a Global Economy. Edinburgh: Edinburgh University Press

CPAG (2015) ESA and abolition of the 'six month rule'. http://www.cpag.org.uk/content/esaand-abolition-six-month-rule (accessed 5.4.16)

Cresswell, J.W. (2013) Qualitative Inquiry \& Research Design. Choosing Among Five Approaches. London: Sage Publications Ltd

Curtis, S. (2010) Space, Place and Mental Health. Surrey: Ashgate Publishing Ltd

Department for Work and Pensions (2017) Personal Independence Payment statistics. https://www.gov.uk/government/collections/personal-independence-payment-statistics (accessed 18.4.17)

DPAC (2016) DPAC's Response to the ending of repeat assessments for severe, lifelong conditions. http://dpac.uk.net/2016/10/dpacs-response-to-damien-greens-announcement-ofending-repeat-assessments-for-severe-lifelong-conditions/ (accessed 5.10.16)

Dreger, S., Buck, C., and Bolte, G. (2014) Material, psychosocial and sociodemographic determinants are associated with positive mental health in Europe: a cross-sectional study. BMJ Open 4: e005095

Duffy, S. (2013) A Fair Society? How the cuts target disabled people. Centre for Welfare Reform

Elgot, J. and Mason, R. (2017) George Osborne's benefit cuts legacy set to come into effect. The Guardian, $1^{\text {st }}$ April

Garthwaite, K.A. (2014) Fear of the Brown Envelope: exploring welfare reform with long term sickness benefits recipients. Social Policy and Administration 48: 782-798

Garthwaite, K.A. (2016) Hunger Pains. London: Policy Press 
Gudmundsdottir, S. (1996) The Teller, the Tale and the One Being Told: The Narrative Nature of the Research Interview. Curriculum Inquiry 26(3): 293-306

Hamilton, S., Pinfold, V., Cotney, ,J., Couperthwaite, L., Matthews, J., Barret, K., Warren, S., Corker, E., Rose, D., Thornicroft, G., Henderson, C. (2016) Qualitative analysis of mental health service users' reported experiences of discrimination. Acta Psychiatrica Scandinavica 134(S446): 14-22

Hills, J. (2014) Good Times Bad Times: The welfare myth of them and us. Bristol: Policy Press

Hudson, R. (2013) Conclusion: divided kingdom? Health, the regions and austerity economics. In Wood, C. (Ed) Health in Austerity. Demos Collection 36: London

Johnson, P. (2014) Introductory Remarks. Institute for Fiscal Studies Autumn Statement Briefing. https://www.ifs.org.uk/uploads/publications/budgets/as2014/as2014 johnson.pdf (accessed 11.4.17)

Joint Strategic Needs Assessment (2013) Stockton Joint Strategic Needs Assessment. http://www.teesjsna.org.uk/stockton/ (accessed 2.12.2013).

Kitson, M., Martin, R., and Tyler, P. (2011) The geographies of austerity. Cambridge Journal of Regions, Economy and Society 4: 289-302

Lupton, R. (2015) The Coalition's Social Policy Record: Policy, Spending and Outcomes 2010-2015. http://sticerd.Ise.ac.uk/dps/case/spcc/RR04.pdf (accessed 5.11.15)

Maclnnes, T., Tinson, A., Hughes, C., Born, T.B., and Aldridge, H. (2015) Monitoring Poverty and Social Exclusion 2015. Joseph Rowntree Foundation

Macintyre S, Ellaway A, Cummins S (2002) Place effects on health: how can we conceptualise and measure them? Social Science and Medicine 55: 125-139. 
Mattheys K., Bambra, C., Warren, J., Kasim, A., and Akhter, N. (2016) Inequalities in mental health and well-being in a time of austerity: Baseline findings from the Stockton-on-Tees cohort study. Social Science \& Medicine Population Health 2: 350-359

Menzies, R., LeFrancois, B.A., and Reaume, G. (2013) Introducing Mad Studies. In B.A. Le Francois, R Menzies and G Reaume. (Eds) Mad Matters. A Critical Reader in Canadian Mad Studies Toronto: Canadian Scholars Press Inc

Mind (2012) Why the WCA isn't Working. http://www.mind.org.uk/information-support/yourstories/why-the-wca-isnt-working/ (accessed 29.12.15)

NHS (2014) Five Steps to Mental Wellbeing http://www.nhs.uk/Conditions/stress-anxietydepression/Pages/improve-mental-wellbeing.aspx (accessed 1.6.15)

Niedzwiedz, C. L. Mitchell, R. J. Shortt, N. K. \& Pearce, J. R. (2016) Social protection spending and inequalities in depressive symptoms across Europe. Social Psychiatry and Psychiatric Epidemiology, pp. 1-10.

Nomis (2012) Labour Market Profile - Stockton-on-Tees

http://www.nomisweb.co.uk/reports/lmp/la/2038432079/report.aspx?town=stockton (accessed 1.10.2013)

Nomis (2015) Labour Market Profile - Stockton-on-Tees.

https://www.nomisweb.co.uk/reports/lmp/la/1946157063/report.aspx (accessed 7.7.16)

Office for National Statistics (2011). Census: Aggregate data (England and Wales) [computer file]. UK Data Service Census Support. Downloaded from: http://infuse.ukdataservice.ac.uk (accessed 03.05.16)

O'Hara, M (2013) Austerity Bites: a journey to the sharp end of the cuts in the UK. Bristol: Policy Press

Patrick, R. (2015) Rhetoric and Reality: Exploring lived experiences of welfare reform under the Coalition. In L. Foster, A. Brunton, C. Deeming and T. Haux (Eds) In Defence of Welfare 2. Social Policy Association.

Pearce, J. (2013) Commentary. Environment and Planning A 45: 2030-2045 
Pemberton, S., Sutton, E., Fahmy, E., Bell, K. (2014) Life on a Low Income in Austere Times. ESRC: PSE UK

http://www.poverty.ac.uk/sites/default/files/attachments/Life\%20on\%20a\%20low\%20income \%20in\%20austere\%20times final report.pdf (accessed 1.4.16)

PSE UK (2013) The Impoverishment of the UK. ESRC.

http://www.poverty.ac.uk/sites/default/files/attachments/The_Impoverishment_of_the_UK_P SE_UK_first_results_summary_report_March_28.pdf (accessed 1.3.15)

Public Health England (2015) Stockton-on-Tees Health Profile 2015. APHO http://www.apho.org.uk/resource/item.aspx?RID=50336 (accessed 1.10.15)

Roulston, K. (2010) Reflective Interviewing: A Guide to Theory and Practice. London: SAGE Publications Ltd

Standing, G. (2014) The Precariat. The New Dangerous Class. London: Bloomsbury Academic

Taylor-Gooby, P. (2012) Root and branch restructuring to achieve major cuts: the social policy programme of the 2010 UK Coalition government. Social Policy and Administration 46(1): 61-82

Townsend, P (1979) Poverty in the United Kingdom. Middlesex: Penguin Books Ltd

Warren, J., Garthwaite, K.A., and Bambra, C. (2014) After Atos Healthcare: Is the Employment and Support Allowance fit for purpose and does the Work Capability Assessment have a future? Disability \& Society 29(8): 1319-1323

WHO and Calouste Foundation (2014) Social Determinants of Mental Health. Geneva: WHO

Wilson, W and Barton, C (2016) Local Housing Allowance and the social rented sector. House of Commons Briefing Paper Number 07833, 20 ${ }^{\text {th }}$ December 
http://researchbriefings.files.parliament.uk/documents/CBP-7833/CBP-7833.pdf (accessed 6.6.17) 